\title{
Metabolic Adaptation to a Low Carbohydrate-High Protein ('Traditional') Diet in Australian Aborigines
}

\author{
${ }^{1}$ K. O'Dea and ${ }^{2}$ R. M. Spargo \\ ${ }^{1}$ Baker Medical Research Institute, Prahran, Victoria and ${ }^{2}$ Kimberley Health, Derby, Western Australia, Australia
}

Summary. We have investigated plasma glucose and insulin responses to $75 \mathrm{~g}$ glucose in 12 young, full-blood Aborigines before and after 2 weeks on a diet derived almost exclusively from seafood. This diet was low in fat, extremely low in carbohydrate and high in protein and was representative of the diet consumed by these people in their traditional lifestyle during those times of the year when very little vegetable food was available.

After an initial weight loss which was probably due to glycogen, salt and water losses associated with the dietary change, body weights stabilised by the end of the first week. Total triglyceride concentrations in fasting plasma fell from $1.32 \pm 0.33$ before the diet to $0.61 \pm 0.08 \mathrm{mmol} / 1 \mathrm{after}$ it, while total cholesterol, which was low initially, did not fall significantly.
There was a small but significant improvement in glucose tolerance and a small reduction in insulin response indicating that the Aborigines had adapted effectively to the very low carbohydrate-high protein diet in the 2 week period. The insulin response to $50 \mathrm{~g}$ protein also fell significantly after the seafood diet. The results suggest that glucose tolerance is not determined solely by the carbohydrate content of the diet, but rather by the availability of carbohydrate either directly or in directly in precursor form as dietary protein.

Key words: Australian Aborigines, diabetes, insulin secretion, glucose tolerance, low carbohydrate-high protein diet, triglycerides.
High prevalence rates for Type 2 (non-insulin-dependent) diabetes mellitus have been reported for Australian Aborigines when they urbanize [1-5]. It has been suggested that metabolic characteristics which favoured survival in the traditional hunter-gatherer lifestyle (the 'thrifty gene' [6]) became detrimental as traditional diet and physical activity patterns were abandoned. Consistent with a metabolism favouring efficient fat deposition, several studies have reported high insulin responses to an oral glucose challenge in Aborigines [2, 7, 8]. We have shown that although this unusually high insulin response was reduced by temporary reversion to traditional lifestyle, it was still significantly higher than in age- and weight-matched Caucasoids [7].

Traditional lifestyle was characterized by a high level of physical activity and a diet derived from a wide variety of animal and vegetable sources. In certain areas of Australia there were periods each year when very little vegetable food was available and consequently the diet was extremely low in carbohydrate. Although we have previously shown that glucose tolerance was not impaired by three months on a low carbohydrate-high protein diet [7], we have no information on short term adaptation to such a diet. We approached this question in the present study by measuring glucose tolerance and insulin secretion before and after 2 weeks on a diet derived exclusively from seafood (i. e. very low carbohydrate-high protein diet). We also measured the insulin response to an oral protein load to see if it was affected by the high protein diet.

\section{Methods}

\section{Subjects}

Twelve full-blood Aborigines (ten women, two men) from the Mowanjum Community, Derby, Western Australia, participated in this study. Their mean age was $24.3 \pm 1.0$ years, mean body weight 66.8 $\pm 3.7 \mathrm{~kg}$ and mean body mass index $23.6 \pm 1.4 \mathrm{~kg} / \mathrm{m}^{2}$ (Table 1). They were weight stable before the study and there were no known diabetic subjects in the group.

\section{Field Study}

The field study was carried out in an isolated location on the northwest coast of Australia $250 \mathrm{~km}$ north-east of Broome (latitude $17^{\circ}$ ). The Aborigines had no access to store foods or beverages during the 
Table 1. The changes in body weight and fasting plasma triglyceride and cholesterol concentrations in 12 Aborigines after 2 weeks on a seafood diet

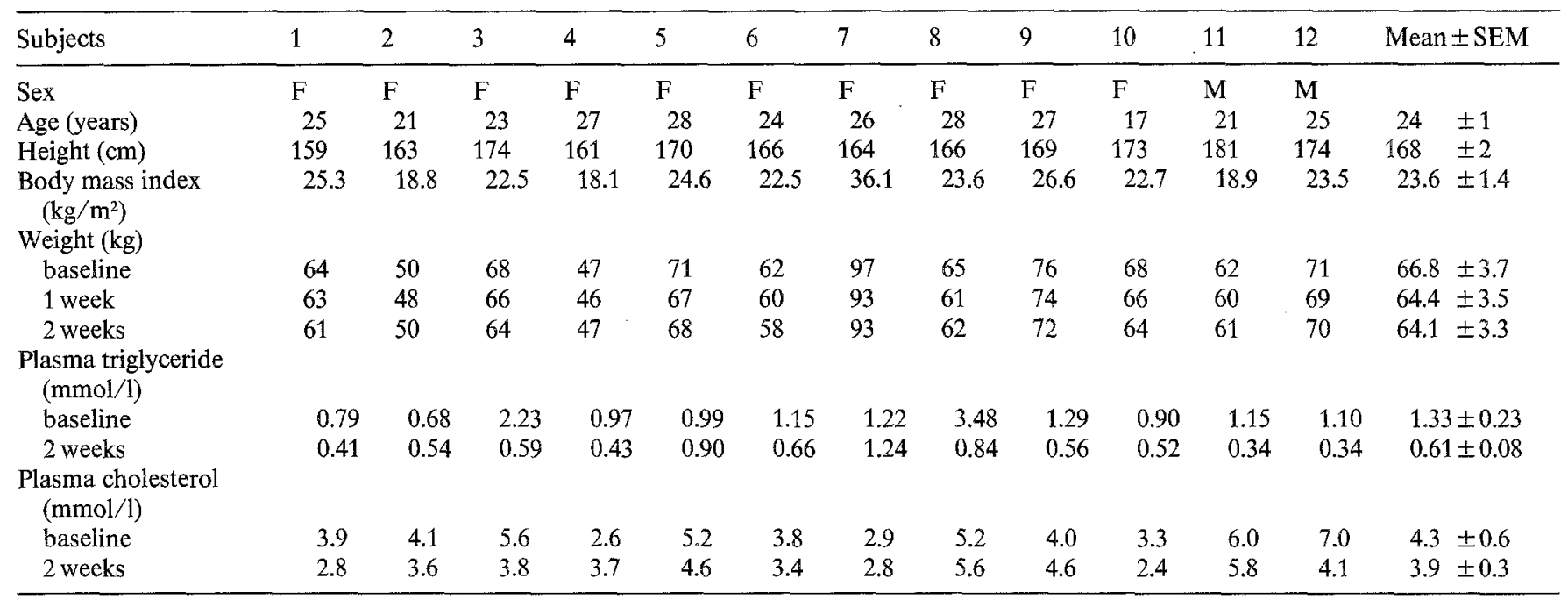

study. One of us (K.O.'D.) was present throughout the study to ensure strict compliance to the experimental diet. The participants travelled from Derby by car and had at least one full day without alcohol before the metabolic tests were performed. The seafood diet was then commenced and 2 weeks later the baseline studies were repeated. The food gathering component of this study did not involve high energy expenditure on the part of the participants since most of the food eaten came from fish caught in nets on the incoming and outgoing tides.

\section{Urban Diet}

The main dietary components were unenriched white flour, white sugar, white rice, carbonated drinks, alcoholic beverages (beer, port), powdered milk and cheap fatty meat. Other than onions and potatoes very little fresh vegetables or fruits were consumed. This diet was high in refined carbohydrate (40-50\%) and fat (40-50\%) and relatively low in protein $(\leqq 10 \%)$.

\section{Experimental Diet}

This diet was derived almost exclusively from seafood. The main source of food was a variety of fish (mullet, whiting, blue salmon, trevally, skippy, catfish) supplemented with shellfish (oysters, mudcrabs, snails, cockles). Small and medium sized fish, crabs, snails etc. were grilled whole on the coals from wood fires, while large fish were sometimes cut up and used for soup. Every 2 or 3 days a handful of fibrous berries were eaten as a prophylaxis against constipation. Samples of seafood eaten were taken for analysis and preliminary results indicate a diet of the following composition: protein 70-75\%, fat $20-25 \%$, carbohydrate $<5 \%$. These analyses were made on raw frozen seafood. The loss of some fat during cooking (grilling etc) cannot be excluded.

\section{Metabolic Studies}

On the 2 days immediately before commencing the experimental diet, the subjects underwent two metabolic tests after a $12 \mathrm{~h}$ overnight fast. An indwelling IV cannula was inserted into a vein in the forearm and kept patent with heparinized saline. A fasting blood sample was taken before the subjects were given either $75 \mathrm{~g}$ glucose ('Glucola') or $50 \mathrm{~g}$ protein ( $250 \mathrm{~g}$ veal: $19.8 \%$ protein, $1.3 \%$ fat) on consecutive days. The meat was consumed over $5-10 \mathrm{~min}$ and zero time was taken as the commencement of eating. Post-prandial blood samples were taken at
$1 / 2,1,2$ and $4 \mathrm{~h}$. These studies were repeated after 2 weeks on the experimental diet.

Blood samples were centrifuged immediately and the separated plasma stored frozen until flown to Melbourne for analysis of plasma glucose, insulin and lipids.

\section{Analytical Methods}

Glucose concentrations were measured in fluoride oxalate plasma by the glucose oxidase method. Immunoreactive insulin concentrations in heparinized plasma were measured using dextran-coated charcoal for precipitation of free hormone after reaction of insulin with commercially available antiserum (Burroughs-Wellcome). Human insulin (Novo) was used as the standard. The range of the insulin assay was 5-200 mU/1 and the interassay coefficient of variation was $8 \%$. Fasting triglyceride concentrations were determined enzymatically after enzymatic hydrolysis using a Technicon autoanalyser. The normal range for triglyceride concentrations in fasting plasma of Caucasoid Australians is $0.5-2 \mathrm{mmol} / 1$. Total cholesterol concentration in fasting plasma was measured colorimetrically after reaction with acetic anhydride and concentrated sulphuric acid using a commercially available kit (Boehringer). The normal range for cholesterol concentration in fasting plasma from Caucasoids is $3.5-6.5 \mathrm{mmol} / \mathrm{l}$.

\section{Statistical Methods}

Statistical analysis of the results was by multiple regression analysis, analysis of variance and Student's paired t-tests.

\section{Results}

The changes in body weights of the subjects in response to the experimental diet are reported in Table 1. Weight loss over the 2 week period was variable $(0-4 \mathrm{~kg})$ and much more pronounced during the first week of the diet (mean $2.4 \mathrm{~kg}$ ) than the second (mean $0.3 \mathrm{~kg}$ ). The four leanest subjects lost the least weight.

Fasting plasma cholesterol concentrations were not significantly affected by the dietary change (Table 1 ). In contrast, fasting plasma triglyceride concentrations fell 
Table 2. The changes in plasma glucose concentrations in 12 Aborigines following $75 \mathrm{~g}$ oral glucose before and after 2 weeks on a seafood diet

\begin{tabular}{|c|c|c|c|c|c|c|c|c|c|c|c|c|c|c|}
\hline \multicolumn{2}{|l|}{ Subjects } & 1 & 2 & 3 & 4 & 5 & 6 & 7 & 8 & 9 & 10 & 11 & 12 & Mean \pm SEM \\
\hline \multicolumn{2}{|l|}{ Age (years) } & 25 & 21 & 23 & 27 & 28 & 24 & 26 & 28 & 27 & 17 & 21 & 25 & $24 \pm 1$ \\
\hline \multicolumn{2}{|c|}{$\begin{array}{l}\text { Body mass index } \\
\left(\mathrm{kg} / \mathrm{m}^{2}\right)\end{array}$} & 25.3 & 18.8 & 22.5 & 18.1 & 24.6 & 22.5 & 36.1 & 23.6 & 26.6 & 22.7 & 18.9 & 23.5 & $23.6 \pm 1.4$ \\
\hline \multicolumn{15}{|c|}{$\begin{array}{l}\text { Plasma glucose } \\
(\mathrm{mmol} / \mathrm{l})\end{array}$} \\
\hline & $1 / 2 h$ & 10.8 & 7.4 & 7.8 & 6.2 & 9.4 & 6.6 & 5.6 & 7.9 & 8.3 & 6.8 & 6.9 & 7.3 & $7.6 \pm 0.4$ \\
\hline & $1 \mathrm{~h}$ & 14.6 & 8.2 & 8.0 & 7.1 & 10.6 & 5.3 & 6.5 & 10.5 & 8.2 & 6.2 & 7.3 & 7.9 & $8.4 \pm 0.7$ \\
\hline & $2 \mathrm{~h}$ & 11.7 & 7.8 & 7.2 & 6.4 & 8.4 & 4.9 & 4.8 & 8.6 & 5.2 & 6.2 & 6.6 & 6.7 & $7.0 \pm 0.6$ \\
\hline & $4 \mathrm{~h}$ & 8.8 & 3.3 & 7.7 & 4.0 & 4.1 & 4.6 & 4.1 & 4.7 & 4.6 & - & 4.1 & 4.1 & $5.1 \pm 0.5$ \\
\hline \multirow[t]{3}{*}{2 weeks } & $\mathrm{Oh}$ & 5.6 & 5.1 & 4.3 & 5.3 & 5.1 & 4.4 & 4.4 & 4.8 & 4.5 & 5.2 & 4.5 & 4.9 & $4.8 \pm 0.1$ \\
\hline & $1 / 2 h$ & 8.5 & 7.4 & 5.0 & 7.2 & 7.7 & 8.5 & 5.2 & 8.3 & 6.2 & 6.7 & 7.3 & 7.2 & $7.1 \pm 0.3$ \\
\hline & $1 \mathrm{~h}$ & 9.4 & 8.5 & 9.1 & 7.4 & 9.4 & 8.9 & 5.3 & 8.9 & 6.7 & 8.3 & 7.0 & 6.9 & $8.0 \pm 0.4$ \\
\hline \multicolumn{2}{|l|}{ baseline } & 44.6 & 26.2 & 29.7 & 23.3 & 30.2 & 20.5 & 20.0 & 30.6 & 23.9 & 25.2 & 24.2 & 24.9 & $26.9 \pm 1.9$ \\
\hline \multicolumn{2}{|l|}{2 weeks } & 29.0 & 21.9 & 32.5 & 23.1 & 26.1 & 26.0 & 18.1 & 24.6 & 20.4 & 26.9 & 20.7 & 23.0 & $24.4 \pm 1.2$ \\
\hline
\end{tabular}

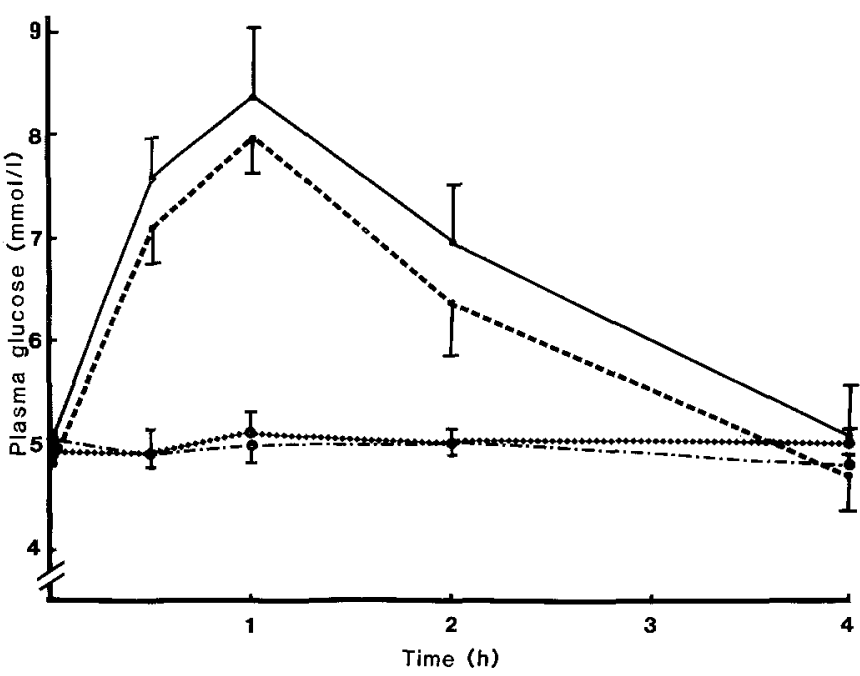

Fig. 1. Change in plasma glucose concentrations in response to $75 \mathrm{~g}$ glucose or $50 \mathrm{~g}$ protein in 12 Aborigines before ( - glucose, $\bullet \bullet \bullet$ protein) and after (-..- glucose, -...- protein) 2 weeks on a seafood diet. Results expressed as mean \pm SEM

to less than half the initial levels after 2 weeks on the seafood diet $(p<0.001)$.

The change in plasma glucose in response to the glucose load before and after the seafood diet is shown in Table 2 and Figure 1 . Three way analysis of variance of these data revealed a small but significant improvement in glucose tolerance in response to the very low carbohydrate diet $(p<0.05)$. Multiple regression analysis indicated that there was no relationship between improvement in glucose tolerance and weight loss. Plasma glucose did not change after the ingestion of the protein load (Fig. 1) either before or after the seafood diet.
The insulin responses to oral glucose before and after the seafood diet are shown in Table 3 and Figure 2. Although peak insulin concentrations in response to oral glucose were not reduced by the diet, three way analysis of variance indicated that the insulin response over the 4-h test period was reduced by the seafood diet $(p<0.05)$. However, multiple regression analysis indicated that the reduction in insulin response was not related to weight loss. The insulin response to the protein load (which was much smaller than to the glucose load) was also significantly reduced after 2 weeks on the experimental diet $(p<0.01)$.

\section{Discussion}

The major finding in the present study was the lack of deterioration of glucose tolerance in response to 2 weeks on a diet which was extremely low in carbohydrate. Indeed, the Aborigines in this study showed a small but significant improvement in glucose tolerance which was accompanied by a similar small reduction in insulin response. Together these findings suggest an improvement in glucose utilization and insulin sensitivity after the high protein-low carbohydrate diet. These changes were not correlated with weight loss in the individual subjects. The weight loss occurred primarily in the first week of the seafood diet and was probably due in large part to the major changes in salt and water balance which occur on low carbohydrate diets $[9,10]$.

Furthermore, it is unlikely that these changes were due to alcohol withdrawal. In a previous study [8] we found no differences in glucose tolerance or insulin responses between two groups of Aborigines closely 
Table 3. The changes in plasma insulin concentrations in 12 Aborigines following $75 \mathrm{~g}$ oral glucose before and after 2 weeks on a seafood diet

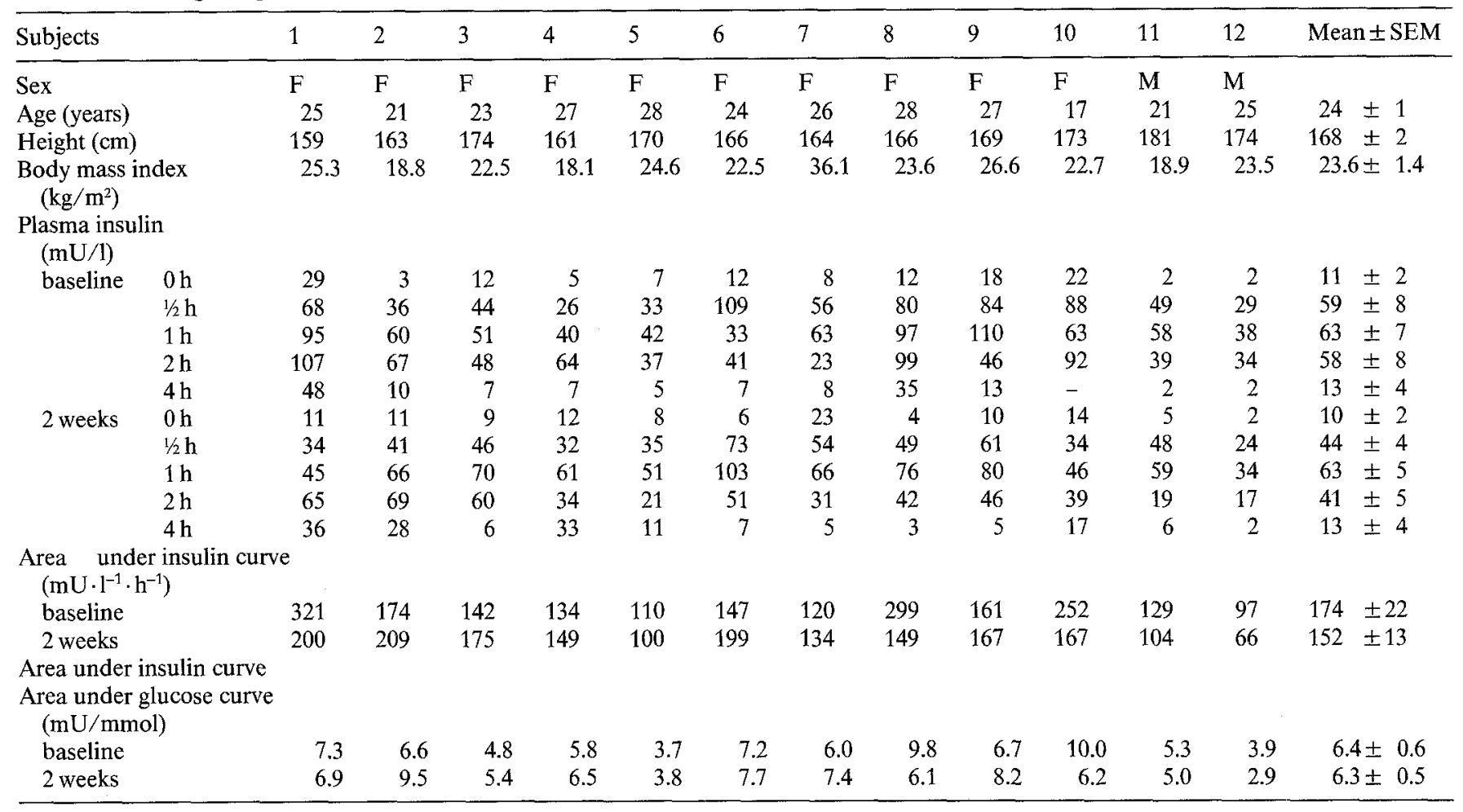

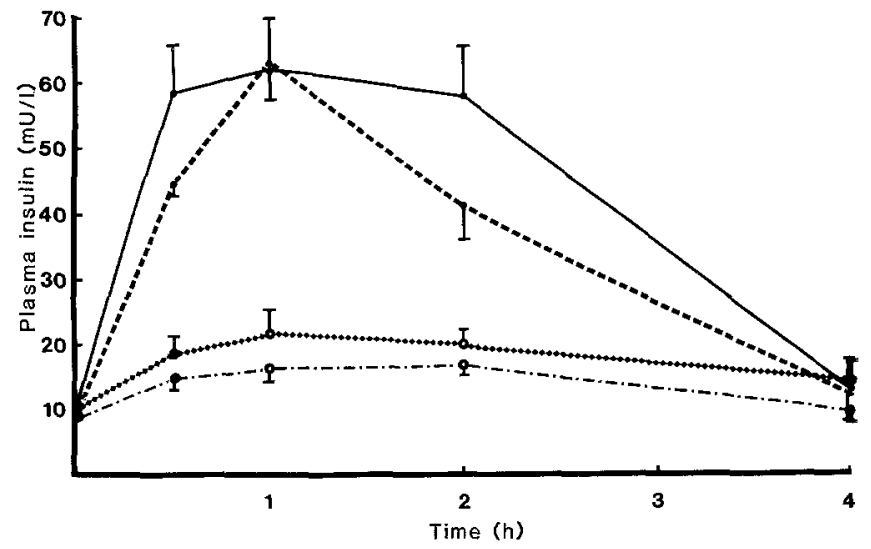

Fig. 2. Change in plasma insulin concentrations in response to $75 \mathrm{~g}$ glucose or $50 \mathrm{~g}$ protein in 12 Aborigines before $(-$ glucose, $\bullet \bullet \bullet \bullet$ protein) and after (---- glucose, $-\cdot \cdots \cdot-$ protein) 2 weeks on a seafood diet. Results expressed as mean \pm SEM

matched for age and body weight but with quite different alcohol intakes: the 'rural' group consumed no alcohol, while the 'urban' group were generally heavy drinkers having abstained for at least one day prior to testing (as in the present study). Nor is it likely that the improvement in glucose tolerance and reduction in insulin response were due to increased physical activity since procuring the experimental diet did not involve high energy expenditure on the part of the participants. Most of the food eaten came from fish caught in nets on the incoming and outgoing tides.

Composition of the diet plays an important role in the pathogenesis and therapy of Type 2 diabetes. Ep- idemiological studies indicate that Type 2 diabetes prevalence in a population is directly related to the energy and fat consumption and inversely related to the carbohydrate content of the diet $[11,12]$. Consistent with this, glucose tolerance has been shown to be impaired by low carbohydrate-high fat diets [13-15] and improved by high carbohydrate diets $[13,14,16,17]$. As a result, it is now widely accepted that, as originally proposed by Himsworth [13], glucose tolerance is determined solely by the carbohydrate content of the diet. However there are few data available on the effect of high protein-low carbohydrate diets on glucose tolerance, which is the essence of the diet studied here. One of the only other published studies of the effects on glucose tolerance was that of Heinbecker [18] on Eskimos in which he found normal glucose tolerance on a high protein-low carbohydrate diet. These results in Eskimos suggest that our observations in Australian Aborigines are not racially determined.

The mechanisms by which low carbohydrate diets which are high in protein preserve glucose tolerance while those high in fat do not, is probably related to the gluconeogenic potential of high protein diets. Elevated glucose levels in response to the ingestion of protein would promote hepatic gluconeogenesis from amino acids entering the liver from the splanchnic circulation. In this way a low carbohydrate diet which was high in protein could maintain the necessary glucose supply to the body whereas one high in fat could not.

The striking fall in fasting plasma triglyceride concentration after the seafood diet was probably due to a 
combination of the high content of $\omega 3$ polyunsaturated fatty acids $[19,20]$ and the low content of carbohydrate and abstinence from alcohol in the experimental diet [7, 8]. Only two of 12 of the baseline triglyceride concentrations were over $2 \mathrm{mmol} / \mathrm{l}(2.23,3.48 \mathrm{mmol} / \mathrm{l})$ and they both fell dramatically $(0.59,0.84 \mathrm{mmol} / 1$ respectively). The other 10 values ranged from 0.8 to $1.29 \mathrm{mmol} / \mathrm{l} \mathrm{be}-$ fore the diet and 0.34 to $1.24 \mathrm{mmol} / 1$ after it. Triglyceride concentrations fell in all but one subject. Undoubtedly withdrawal of alcohol contributed to the marked fall in the two subjects who were high initially and may have contributed to a small extent in the others. However, falls of this magnitude have been reported in studies of fish feeding in Caucasoid subjects where alcohol was not a complicating factor $[19,20]$. Fasting plasma cholesterol concentrations were similar to levels reported in other studies with people from this area [7, 8]. That they did not change may have been due to the high content of polyunsaturated fatty acids in seafood.

The mild impairment of glucose tolerance and high insulin response to oral glucose observed in this group of Aborigines are very similar to data obtained from other Aborigines from the same area [8]. These metabolic characteristics may have been important to survival in the traditional lifestyle by favouring efficient fat deposition - the 'thrifty gene' [6] - on a diet in which the carbohydrate content was seasonally variable. As the Aborigines change from the traditional to the urban diet which is high in refined carbohydrate, it is possible that these metabolic characteristics become detrimental and facilitate the development of obesity and diabetes.

Type 2 diabetes has been an increasing health problem in Aboriginal communities as they make the transition from traditional to urban lifestyle and conventional therapies have failed for a variety of cultural, historic and economic reasons. Adopting elements of the traditional lifestyle periodically would provide a practical and acceptable approach to the problem.

In conclusion, the present study has demonstrated that glucose tolerance is not determined solely by the amount of carbohydrate in the diet, but rather by the availability of carbohydrate either directly in the diet or in the precursor form as dietary protein. These results, together with those from a previous study of longer duration [7], suggest that such a diet may have an important role in the primary prevention of diabetes in Australian Aborigines.

\footnotetext{
Acknowledgements. We would like to thank the people of the Mowanjum Community in Derby without whose invaluable help and cooperation this study could not have been carried out. We are also very grateful to $M$. Lintermans and $J$. Turton for their expert technical assistance, to J. Gipps for her invaluable advice in the statistical analyses, to Ames Pharmaceuticals who generously donated the 'Glucola' and assisted with the transport of supplies to and from the field and to Drs. P. Nestel and A. McLean for their helpful discussions during the preparation of this manuscript. This work was supported by a grant from the National Health and Medical Research Council of Australia.
}

\section{References}

1. Wise PH, Edwards FM, Thomas DW, Elliott RB, Hatcher L, Craig R (1970) Hyperglycemia in the urbanised Aboriginal. The Davenport Survey. Med J Aust 2:1001-1006

2. Wise PH, Edwards FM, Craig RJ, Evans B, Murchland JB, Sutherland B, Thomas DW (1976) Diabetes and associated variables in the South Australian Aboriginal. Aust NZ J Med 6: 191-196

3. Bastian P (1979) Coronary heart disease in tribal Aborigines - the West Kimberley Survey. Aust NZ J Med 9: 284-292

4. Winterbotham HJ (1961) Diabetes mellitus at Mabuiag Island, Torres Straits, 1960. Med J Aust 1: 780-781

5. Duffy P, Morris H, Neilson G (1981) Diabetes mellitus in the Torres Strait region. Med J Aust 1: 8-11

6. Neel JV (1963) Diabetes mellitus: a "thrifty" genotype rendered detrimental by progress? Am J Hum Genet 14: 353-362

7. O'Dea K, Akerman K, Spargo RM (1980) The effect of transition from traditional to urban lifestyle on the insulin secretory response in Australian Aborigines. Diabetes Care 3:31-37

8. O'Dea K, Spargo RM, Nestel PJ (1982) Impact of westernization on carbohydrate and lipid metabolism in Australian Aborigines. Diabetologia 22: 148-153

9. Bloom WL (1962) Inhibition of salt excretion by carbohydrate. Arch Intern Med 109: 26-32

10. Bloom WL, Azar GJ (1963) Similarities of carbohydrate deficiency and fasting. Arch Intern Med 112: 333-337

11. Himsworth HP (1949) Diet in the aetiology of human diabetes. Proc Roy Soc Med 42: 323-326

12. West KM, Kalbfleisch JM (1971) Influence of nutritional factors on prevalence of diabetes. Diabetes 20:99-108

13. Himsworth HP (1935) The dietetic factor determining the glucose tolerance and sensitivity to insulin of healthy men. Clin Sci 2: 67-94

14. Sweeney JS (1927) Dietary factors that influence the dextrose tolerance test. Arch Int Med 40: 818-830

15. Hales CN, Randle PJ (1963) Effects of low-carbohydrate diet and diabetes mellitus on plasma concentrations of glucose, non-esterified fatty acid, and insulin during oral glucose tolerance tests. Lancet 1: 790-794

16. Kieh TG, Anderson JW, Ward K (1976) Beneficial effects of a high carbohydrate, high fibre diet on diabetic men. Am J Clin Nutr 29: 895-899

17. Simpson RW, Mann JI, Eaton J, Moore RA, Carter R, Hockaday TDR (1979) Improved glucose control in maturity-onset diabetes treated with high carbohydrate-modified fat diet. Brit Med $\mathbf{J} 1$ : $1753-1756$

18. Heinbecker P (1928) Studies on the metabolism of Eskimos. J Biol Chem 80: 461-475

19. Harris WS, Connor WE (1980) The effects of salmon oil upon plasma lipids, lipoproteins and triglyceride clearance. Trans Assoc Am Phys XLIII: 148-155

20. Bronsgeest-Schoute HC, van Gent CM, Luten JB, Ruiter A (1981) The effect of various intakes of $\omega 3$ fatty acids on the blood lipid composition in healthy human subjects. Am J Clin Nutr 34: 1752-1757

Received: 25 January 1982

and in revised form: 22 June 1982

Dr. Kerin O'Dea,

Baker Medical Research Institute

Commercial Road, Prahran, Victoria, 3181

Australia 